\title{
Development and Utilization of Tongyu New Year Picture Cultural Industry
}

\author{
Yimeng Zou ${ }^{1}$ \\ ${ }^{1}$ Baicheng Normal University
}

Key words: Tongyu new year pictures, Innovation-centered, Culture-based, Tourism intermediary, Industry brand

\begin{abstract}
Tongyu County situates in the south of Baicheng City, Jilin Province. It is a place with abundant cultural resources, heavy local characteristics and much intelligence. Tongyu new year pictures have distinct local colors and are a cultural brand well-known in China and even the whole world. How to utilize and protect this unique local folk culture and develop it healthily remains a proposition for Scientific Outlook on Development. The author believes that it is the fundamental essence for the healthy and stable development of cultural industry to have a batch of talents with cultural innovation views. The exploration, collection, organization, protection and industry development and utilization of the unique cultural resource of Tongyu new year pictures relies on these innovative and brave talents.
\end{abstract}

\section{Introduction}

In the Sixth Plenary Session of the 17th Central Committee of the Chinese Communist Party in October 2011, the Report of CPC Central Committee's Decisions about Deepening Cultural System Reform and Pushing Cultural Development and Prosperity pointed out that "It is an important way for satisfying people's diversified spiritual and cultural demands under socialist market economy conditions to develop cultural industry. The society must adhere to the advanced socialist culture, putting social benefit at the priority, the unity of social benefits and economic benefits. According to the comprehensive, balanced and continuable demands, the society must push the great-leap-forward development of cultural industry so that it can become a new economic growth point, an important fulcrum of strategic restructuring of the economy and an important point of strength for change of the economic development mode, thereby providing an important support for promoting scientific development." The development and utilization of Tongyu new year pictures must seize this historical opportunity occurring only once in a thousand years and promote comprehensive development of Tongyu economy.

\section{Introduction to Tongyu new year pictures}

Tongyu County is a place with abundant cultural resources, heavy local characteristics and much intelligence. Tongyu new year pictures have distinct local cultural brand; they bear the dignified feelings of the black land and manifest ruggedness and violence of northeaster, which can be said "it wins out Yangliuqing County by lofty sentiments and is stronger than Taohuawu by generosity". It possesses unique artistic charm and infection. Especially Tongyu new year pictures, which can show local people's ardent love and positive expectations for beautiful life. These positive and upward intensional characteristics are essential conditions to develop cultural industry. Compared with other large and medium cities in China, Tongyu County does not have advantages no matter in platform, region and resources. However, in the present day with "new economic growth point and strategic restructuring of the economy" and "mass entrepreneurship and innovation", how can we adapt to new situations and choose development direction of Tongyu? We believe that it is the best rational choice to explore, collect, organize, rescue and protect Tongyu new year pictures and rely on this unique cultural resources to do industry development and utilization so that Tongyu new year pictures can walk out of this embarrassed place towards broad market. We should take over the art, make it industry chain, transcend history, build brand, present the miracle from folk painting art 
palace of Horqin Grassland in the west of Jilin to all Chinese people and even the whole world so that both Tongyu new year pictures and Tongyu economy can receive good harvest.

\section{“Innovation-Centered”, Creating Industry Brand}

Innovation is the spirit and essence of cultural industry development and it has the magic function of working miracles. Therefore, local places should make use of their regional cultural resources, treat local culture as a kind of precious material resources so as to make industry brand of their industry. Regional cultural resources are colorful in representation forms. They stimulate contemporary people to yearn for beauty and pursue aesthetics. These yearning and pursuit for aesthetics need excellent people who can understand cultural innovation to complete. It is a systemic system with links connecting each other. Innovative achievements need the recognition and confirmation of time, history and developing age. Local places should take advantage of modern media to expand the popularity and reputation of Tongyu new year pictures, hire high-end talents to pack and generalize and promote market recognition and acceptance forces of Tongyu new year pictures in art collection industry. Lin Chao, vice dean of School of Media and Animation, Central Academy of Fine Art, said that "Now lots of medium and small cities do not know how to develop cultural innovation industry or develop it blindly. Actually, they do have the treasure in their hands. They should respect and love traditional culture and combine new development modes."

Cultural innovation industry is a new concept in economic development. It develops rapidly and has become one of the symbols of economic and cultural development. It can combine science and technology with cultural art effectively. Tongyu County has profound cultural and art details as well as traditional cultural resources. It should comply with development trend of current cultural industry and treat cultural innovation industry which takes Tongyu new year pictures as characteristics as center, transform rich cultural resources to productivity and promote comprehensive development of economic society of Tongyu and even the whole Baicheng.

When developing Tongyu new year pictures-centered cultural innovation industry, we should also be aware that there are some problems. The author believes that we should be brave to "cross the boundary" and align with film and television industry to push out cartoons and TV series which take Tongyu new year pictures as subjects. For example: figures, animals, plants and scenes with local characteristics in Tongyu new year pictures can be used as the creation materials of cartoons and TV series. We should dare to "manage", advertise and develop these cartoons and TV series, make figures, animals and plant images in Tongyu new year pictures into artworks and form distinct local cultural industry chain. We should dare to "packaging”. Folktales about Horqin Grassland are numerous, so we can consider to packaging and deduce them into the form of Tongyu new year pictures, make them to products and push them to the market so that they can form industrialization and make them to brands. Modern media technology and excellent folk traditional cultural art can be combined perfectly so that materials come from people's life and serve people in turn after artistic refining and in the end, excellent cultural and artistic works with ideological level, artistry and ornamental value that people love can be created.

We should take art as the entry point and establish tourism crafts which take Tongyu new year pictures as the streamline, organize folk painting, calligraphy, paper-cut, reed-knitting, wicker, ball-point pictures, pictures not painted with pens, stone carving, root carving, fishbone carving with Tongyu new year pictures characteristics and local cultural intension and develop folk art with local characteristics.

\section{“Culture-based”, enriching industry brand}

Culture is the total of material wealth and spiritual wealth human beings create. With the appearance of human beings, culture rises, grows and evolves in response with the proper time, which is the necessity of human's social development and progress. The unique features of a local environment always give special characteristics to its inhabitants and the unique features of a local 
culture always influence inhabitants living there. Chinese culture is extensive and profound, so we should explore local culture with local characteristics without neglecting any culture. We should adhere to the purpose that developing cultural industry should serve people, adhere to cultural transmission and cultivate new forces of culture. Tongyu new year pictures root deep in the black land. Inheriting culture and transmitting civilization is not only the demands of folk panting art, but also the industrial demands for its development. Taking cultural art as the growth point of Tongyu economy makes the finishing point and injects fresh vitality. Firstly, the combination of Tongyu new year pictures with modern architectural decoration design industry should be promoted. Characteristic decoration sample projects can be launched in local restaurants and other service industries to make decoration styles with distinct northeast characteristics and form strong decoration and good visual effects as well as modern new year pictures with traditional cultural characteristics; secondly, infusion with modern newly-developing media industry should be explored and cooperation and butt joint with Baicheng Fenglei Company should be launched so that Tongyu new year pictures can be integrated into Internet game industry; game interface artistic design should be improved with Tongyu new year pictures; in the meantime, relying on the Internet platform of Fenglei Game, influences and transmissibility of Tongyu new year pictures can be further enlarged; thirdly, integration with modern garden industry should be promoted with the agglomeration effect, opening effect and brand effect of Mobao Garden of Tongyu County; setting special forums and presenting intensively so that culture of Tongyu new year pictures will never change and forms of the industry keep bringing forth the fresh.

Here, we should understand urban gardening in Tongyu County, which is Mobao Garden. Mobao Garden in Tongyu County is an urban gardening construction integrating calligraphy and painting and there is a special forum subjecting from Tongyu new year pictures. It reproduces the most excellent 10 pieces of Tongyu new year pictures in artistic form of Jingdezhen porcelain and ceramics, which has special flavors and carries forward and inherits Tongyu new year pictures art. Everything happened in Mobao Garden has been in the first rank of cultural and artistic protection and inheritance, and it can be said to be the scaled-down version of cultural and industrial utilization of Tongyu new year pictures. It brings cultural enlightenments and cultural influences of many aspects. The author believes that the first thing we should do is to prepare to build a Tongyu County "New Year Picture Museum" and collect and organize material objects of Tongyu new year pictures, such as manuscript, media materials, new year picture miniatures and so on. In this way, Tongyu new year pictures can be protected well and leave previous folk cultural heritage to Yongyu people; secondly, exploring cultural intension of Tongyu new year pictures, carrying out Tongyu new year pictures cultural education activities extensively, holding Tongyu new year pictures series lectures regularly, enriching the spiritual and cultural lives of Tongyu people; basic roles of cultural inheritance and innovation is the essence of national education; setting excellent traditional culture locally_school-based curriculum of Tongyu new year pictures , strengthening excellent traditional cultural teaching research base construction, having "intangible cultural heritage" to enter the campus; in addition, using elaborately decorated Tongyu new year pictures to decorate the environment in various big hotels in Tongyu County, improving cultural taste and cultural intension of Tongyu and building cultural atmosphere.

\section{“Tourism intermediary”, popularizing industry brand}

Social forces and market advantages should be exerted sufficiently so that tourism can be combined with culture closely and a batch of tourism projects with local cultural characteristics can be constructed; new breakthroughs in tourism industry should be sought to increase the forces of inviting investment and promote economic development of the county. Deep combination of tourism and culture should be propelled further to enrich the intension of rural tourism and improve the taste of rural tourism; local places should try hard to create tourism cultural industry integrating history, culture, ecological tourism and relaxation holiday. Only by integrating the spirit of culture can resource tourism industry be more lively and durable. Cultural industry can be more influencential and have more transmissibility by integrating the element of tourism. Local places 
should explore the joint point and integrating point of local tourism industry and Tongyu new year pictures industry should explore tourism products and souvenirs which take Tongyu new year pictures as major characteristics.

According to real situations of tourism cultural industry development in He Town, Tongyu, the author believes that to complete the service function of tourism industry, we should implement "unified planning, unified development, unified construction and unified management" to tourism industry. Specifically, there are the following suggestions:

Firstly, constructing cultural and ecological scenic spot. Strengthening the construction of Xianghai national natural conservation area, BaoLaWenDu apricot blossom scenic spot and Xinglong Mountain Mongolia Huangyu scenic spot. We should refine tourism development plan further, grasp tangible and intangible combination of Horqin Grassland local culture, develop and protect them together. Tongyu new year pictures field fabrication studio should be established in scenic spots so that tourists can visit the manufacturing process closely and be personally on the scene. In this way, Tongyu new year pictures can be integrated in all element links of the tourists such as eating, living, travelling, shopping and so on and Tongyu new year pictures can be transmitted faster, further and wider.

Secondly, developing tourism series products and improving disadvantages of Tongyu new year pictures such as large picture, bad picture-mounting and difficult storage. Instead, they can be processed to small and exquisite pictures, delicate mounting, exquisite drawing, sophisticated technology, convenient take-away, storage and collection. Characteristic regional culture with Horqin Grassland characteristics can be integrated into tourism products and transform human landscape into tourism resources.

Thirdly, integrating history, culture, folk-custom and ecological resources. We should also introduce tourism as media: historical tour_—visiting Tongyu County Xinglong Town Neolithic Period Oboo sites; cultural tour__ visiting Tongyu New Year Pictures Museum and Mobao Garden Urban Garden, visiting "Er'lang Temple” and "Xianghai Temple” Tibetan Buddhism Temple; folk tour___entering Uland Tara Mongol Folk Customs Village, Yuyangdian Mongol Cultural Festival, appreciating Mongol characteristic projects such as horse racing, archery, wrestling and so on; enjoying Mongol roast whole lamb, handgrip meat, parched rice, milk tea and beautiful wine; the white hada will bring unique blessings of Mongolian; enjoying infinite joy brought by the broad Horqin Grassland. Ecological tour_roaming in Xianghai national natural conservation area, BaoLaWenDu apricot blossom scenic spot and Xinglong Mountain Mongolia Huangyu scenic spot. Integrating historical culture, ecological natural sightseeing, relaxation holiday so as to promote new tourism cultural industry with Tongyu new year pictures as major characteristic.

In Strengthening Chinese Culture Soft Power, Qi Yongfeng and Li Pingfan said that "Cultural industry is the necessary way to emancipate and develop cultural productivity under market economy conditions and it is the material and effective carrier of culture soft power, reflecting development tendency with culture and economy penetrating into each other. A country and nation's values, ideology and behavioral patterns can only be transmitted and spread to the whole world by scale cultural industry operation and penetrated to millions of people's life practice. Cultural industry can satisfy people's ever increasing diversified cultural consumption demands. Today, all countries with strong soft power all have advanced cultural industry. With the rapid development of science and acceleration of globalization, cultural transmission presents the trend of globalization and ways and carriers of cultural transmission become even more complicated and diversified. Development degree of cultural industry determines a country's cultural transmission degree to some extent and cultural industry has become an important way for cultural transmission.”

\section{Conclusion}

Local cultural resources are important footstone for the development of tourism and are a new growth point of tourism economy. Currently, cultural integration is becoming an unstoppable trend. 
Protecting, developing and utilizing Tongyu new year pictures cultural resources, accelerating construction tourism culture with continuity, peculiarity and innovation so that historical and cultural elements and rural recreational travel reciprocate each other and bring out the best in each other. The content and subjects of Tongyu new year pictures are closely related to people's life, adding festival joyful atmosphere to people, beautifying the environment and enjoying people's love. Development and utilization of Tongyu new year pictures cultural industry should adhere to the folk characteristics of Tongyu new year pictures, adhere to the way of cultural openness and innovation as well as the purpose of mass culture and characteristic culture.

\section{References}

[1] J.C. Feng. Note of New Year Pictures [M]. Yinchuan: Ningxia People’s Publishing House, 2007 (In Chinese)

[2] J.C. Feng. Discovery of New Year Pictures [M]. Harvest, 2009(1) (In Chinese)

[3] Z.P. Jie. Vanished Folk Art New Year Pictures [M]. Taiyuan: Shanxi Ancient Books Press, 2004 (In Chinese)

[4] C.H. Zhang etc. Techniques of New Year Pictures [M]. Shijiazhuang: Hebei Art Press, 1982 (In Chinese)

[5] Compiled by Y.T. Gai. Tongyu New Year Pictures [C]. People’s Government of Tongyu County, 2007 (In Chinese)

[6] Y.X. Sun. A Compilation with Generations of Endeavors [N]. Baicheng Daily, 2008.1.21 (In Chinese) 